\title{
Does disrespect and abuse during childbirth differ between public and private hospitals in Southeast Nigeria
}

Ijeoma Nkem Okedo-Alex ${ }^{1,2^{*}}$ (D, Ifeyinwa Chizoba Akamike ${ }^{1}$, Irene Ifeyinwa Eze ${ }^{1}$ and

Chika Nwamma Onwasigwe ${ }^{1}$

\begin{abstract}
Background: Disrespect and Abuse (D\&A) during childbirth represents an important barrier to skilled birth utilization, indicating a problem with quality of care and a violation of women's human rights. This study compared prevalence of D\&A during childbirth in a public and a private hospital in Southeast Nigeria.
\end{abstract}

Methods: This study was a cross-sectional study among women who gave birth in two specialized health facilities: a public teaching and a private-for-profit faith-based hospital in Southeast Nigeria. In each facility, systematic random sampling was used to select 310 mothers who had given birth in the facility and were between 0-14 weeks after birth Study participants were recruited through the immunization clinics. Semi-structured, interviewer-administered questionnaires using the Bowser and Hills classification of D\&A during childbirth were used for data collection. Data were analyzed using SPSS version 20 at 95\% significance level.

Results: Mean age of the participants in the public hospital was $30.41 \pm 4.4$ and $29.31 \pm 4.4$ in the private hospital. Over three-fifths $(191 ; 61.6 \%)$ in the public and 156 women $(50.3 \%)$ in the private hospital had experienced at least one form of D\&A during childbirth [COR1.58; 95\% Cl 1.15, 2.18]. Abandonment and neglect [Public153 (49.4\%) vs. Private: 91 (29.4\%); cOR2.35; 95\% Cl. 1.69, 3.26] and non-consented care [Public 45 (14.5\%) vs. Private 67(21.6\%): cOR0.62; $95 \% \mathrm{Cl} .0 .41,0.93]$ were the major types of D\&A during childbirth. Denial of companionship was the most reported subtype of D\&A during childbirth in both facilities [Public 135 (43.5\%) vs. Private66 (21.3\%); cOR2.85; 95\% Cl. 2.00, 4.06]. Rural residents were less likely to report at least one form of D\&A during childbirth (aOR 0.53; Cl 0.35-0.79).

Conclusion: Although prevalence was high in both facilities, overall prevalence of D\&A during childbirth and most subtypes were higher in the public health facility. There is a need to identify contextual factors enabling D\&A during childbirth in public and private health care settings.

Keywords: Respectful maternity care, Disrespect and abuse during childbirth, Mistreatment during childbirth, Intrapartum care, Facility-based childbirth, Quality of care, Nigeria

\footnotetext{
*Correspondence: ijeomaninadr@gmail.com

${ }^{1}$ Department of Community Medicine, Alex Ekwueme Federal University

Teaching Hospital Abakaliki, Abakaliki, Ebonyi State, Nigeria

Full list of author information is available at the end of the article
}

\section{Background}

In every country and community worldwide, pregnancy and childbirth are significant events in the lives of women and their families. Every woman has the right to the highest attainable standard of health, which includes the right to dignified, respectful health care throughout pregnancy and childbirth, as well as the right to be free 
from violence and discrimination $[1,2]$.The World Health Organization's (WHO's) quality of care framework for maternal and newborn health $(\mathrm{MNH})$ care contains eight domains, three of which relate to women's experience of care and include effective and responsive communication, care provided with respect and dignity and social and emotional support of the woman's choice [3, 4]. While disrespect and abuse (D\&A) of women may occur throughout pregnancy, childbirth and the postpartum period, women are particularly vulnerable during childbirth. Such practices may have direct adverse consequences for both mother and newborn [2]. Women who have previously been treated disrespectfully during childbirth and those hearing from their experiences may avoid facility childbirth, even if they have complications. This may contribute to increased maternal and perinatal mortality and morbidity. Such avoidable complications include obstructed labour, birth asphyxia, severe bleeding after childbirth, post-childbirth maternal and neonatal infections in addition to the negative psychological effects on women [5-7].D\&A during childbirth can act as a more powerful deterrent to current and/or future skilled birth care than any other more commonly recognized deterrent such as geographic and financial obstacles [8]. According to the 2018 Nigerian Demographic and Health Survey (NDHS), only $39 \%$ of births by Nigerian women occurred in health facilities and 43\%were assisted by skilled birth attendants. Unskilled providers such as traditional birth attendants and relatives/friends assisted in $42 \%$ of births, while $11 \%$ had no external assistance during childbirth [9]. Although this national data did not explore D\&A during childbirth, studies have found that D\&A undermined utilization of health facilities for births and encouraged traditional birth attendance $[10,11]$.

In 2010, Bowser and Hill described in a landscape analysis seven categories of D\&A during childbirth in facilities: physical abuse, non-consented clinical care, non-confidential care, non-dignified care, discrimination, abandonment/denial of care and detention in health facilities. ${ }^{8}$ D\&A has further been re-conceptualized as mistreatment during childbirth which is inflicted not only by individual providers, but also by health systems as a whole when conditions in facilities deviate greatly from accepted standards of care in infrastructure, staff requirements, equipment and supplies needed to provide that care $[7,12]$.

Globally, some studies have shown that non-use or delayed use of health facilities for childbirth have been reported due to poor quality of care and D\&A received in health facilities alongside other social determinants of health [13-17]. Occurrence of D\&A during childbirth has been explored by mostly qualitative studies, but few have used a mixed-methods approach to compare experiences of women in public and private health facilities [7, $10,15,18-27]$. The objective of this study was to compare prevalence and forms of D\&A during childbirth in public and private specialized healthcare settings in Southeast Nigeria.

\section{Methods \\ Study Area}

The study was conducted in two hospitals offering specialized care: a private-for-profit specialist hospital located in Afikpo North Local Government Area and a public tertiary hospital located in Abakaliki Local Government Area, both in Ebonyi State, Nigeria. These two hospitals were selected based on their obstetric work load and patronage. Both hospitals are referral facilities with patronage from urban and rural areas within the State. On a monthly basis, an average of 85 births occurs in the private hospital while the public hospital records 150 births.

The private-for-profit health facility is a specialist faithbased hospital. Clinical care in this hospital includes obstetrics and gynecology, pediatrics, surgery, internal medicine, general outpatient care and accident and emergency care. Recently, the hospital began residency programs for family medicine and obstetrics and gynecology. The immunisation clinic holds once a week with an average number of 100 children per clinic day.

The public health facility is the only teaching hospital in Ebonyi State. Some departments are obstetrics and gynaecology, paediatrics, internal medicine, surgery, community medicine and the adult accident and emergency unit. The immunization clinic holds twice a week and has about 80 children per clinic day.

\section{Study Design and Population}

This study was a comparative cross-sectional study among women who attended child immunization clinics fourteen weeks or less after childbirth in the two health facilities.

Minimum sample size was calculated with a power of $80 \%$, an anticipated non-response rate of $10 \%$ and a significance level of $5 \%$ at 299 women per hospital [28]. A total of 620 women, 310 participants per hospital, was selected for the study.

Systematic random sampling was used to select the study participants. Duration of recruitment was 10 weeks per facility. Using the immunization clinic registers, the sampling interval (K) was calculated by dividing average number of attendees by the number of study participants to be recruited that day. Simple random sampling technique (ballot method) was used to select the first participant in both hospitals [28, 29]. When the selected 
participant using the systematic scheme was not eligible, she was dropped and the next eligible participant recruited until the desired sample size was realized. Noneligibility was defined as: childbirth not in the two hospitals and $>14$ weeks after birth.

\section{Data Collection Instruments}

The instrument for this study was a pre-tested semistructured interviewer-administered questionnaire adapted from a previous study [18]. The first section of the questionnaire was used to collect information on socio-demographic characteristics, including age, marital status, religion, place of residence, occupation and educational level. The second section collected information on the seven Bowser and Hill categories of D\&A during childbirth: physical abuse (5 questions), non-consented care (7 questions), non-confidential care (6 questions), non-dignified care (5 questions), discriminatory care (6 questions), abandonment of care (5 questions) and detention in the health facility (3 questions) [8]. D\&A during childbirth was said to have occurred if the participant answers yes to any of the specific questions in the questionnaire.

\section{Data Collection Methods}

Data collection was carried out by the researcher and five trained research assistants. The assistants were resident doctors in Community medicine, who are uninvolved in the continuum of care of the women. They were trained on a brief overview of D\&A during childbirth and different types, specific objectives of the study and how to administer the questionnaire. Training lasted for three hours. Pre-testing of the questionnaire was done among women ( $5 \%$ of the sample size) who met the inclusion criteria in another health facility in Abakaliki. Issues detected during pre-testing such as rephrasing of questions and typographic errors were addressed. A reliability test, using data from the pre-testing, yielded a Cronbach's alpha value of 0.818 . The questionnaires were administered in the health facility and took approximately seven minutes to fill.

\section{Measurement of variables}

Socio-demographic characteristics (age, marital, educational and employment status, place of residence, religion, socio-economic status) and duration between childbirth and date of the survey were independent variables. STATA statistical software version 12 [30] was used to develop the socio-economic index, using Principal Component Analysis (PCA). Input to the PCA included information on estimated monthly family income, ownership of eight household items that included television, generator, microwave, electric pressing iron, fridge, gas cooker, car and air conditioner. For calculation of distribution cutting points, quartiles $(\mathrm{Q})$ were used as Q1 poorest, Q2 the very poor, Q3 the poor and Q4 least poor [31]. This was further dichotomized into low socioeconomic class (Q1- Q2) and high socio-economic class (Q3-Q4). Each participant was assigned a wealth index score of the household.

Dependent variables were prevalence of at least one type of D\&A during last childbirth and different forms of D\&A. Prevalence of D\&A during childbirth was assessed using 'Yes' and 'No' questions on ever experiencing any form or category of D\&A. Each question under the different categories of D\&A during childbirth was assessed with binary options (Yes' and 'No). The proportion of participants who answered 'Yes' to any of the forms of D\&A under each category was taken as the prevalence of experiencing D\&A during childbirth. The proportion of participants who answered 'Yes' to any of the questions in the seven sub-categories of D\&A, was used to compute the prevalence of each category and form of D\&A during childbirth.

\section{Data analysis}

A computer-based Statistical Package for Social Sciences (SPSS) for Microsoft Window version 20 software [32] was used for data analysis. Frequency tables were used for descriptive statistics of the variables and relevant means, standard deviations and proportions were calculated. Means and range of D\&A during childbirth were calculated.

Frequencies and proportions were calculated for categorical variables while means and standard deviations were calculated for numeric/quantitative variables. Proportions of socio-demographic characteristics, prevalence of at least one form, categories and sub-categories of D\&A during childbirth were compared between the women in the public and private hospitals using chisquare statistics at $5 \%$ level of significance while mean age was compared using student $\mathrm{t}$-test (difference of two means) at the same level of significance. Chi square statistics were also used to assess the relationship between prevalence of at least one form of D\&A during childbirth and socio-demographic characteristics. Independent variables with $p<0.20$ were included in a multivariable logistic regression model to determine predictors of the occurrence of at least one form of D\&A during childbirth.

\section{Results}

Mean age of the participants in the public hospital was higher than that in the private hospital $(30.41 \pm 4.4$ vs. $29.31 \pm 4.4 ; p=0.002)$. More participants from the public hospital had post-secondary education $(81.9 \%)$ than those in the private hospital $(60.0 \%)(p=0.001)$. A greater 
Table 1 Socio-demographic and household characteristics of the participants

\begin{tabular}{|c|c|c|c|}
\hline Variable & $\begin{array}{l}\text { Private hospital } \\
n=310 \\
(\%)\end{array}$ & $\begin{array}{l}\text { Public } \\
\text { hospital } n=310 \\
(\%)\end{array}$ & $p$ value \\
\hline Age (years) & & & 0.090 \\
\hline $15-24$ & $31(10.0)$ & $18(5.8)$ & \\
\hline $25-34$ & $232(74.8)$ & $233(75.2)$ & \\
\hline $35-44$ & $47(15.2)$ & $59(19.0)$ & \\
\hline Mean age (mean $\pm S D$ ) & $29.31 \pm 4.4$ & $30.41 \pm 4.4$ & $0.002^{*}$ \\
\hline \multicolumn{4}{|c|}{ Marital status } \\
\hline Currently married & $283(91.3)$ & $302(97.4)$ & $0.001 *$ \\
\hline 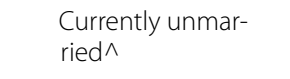 & $27(8.7)$ & $8(2.6)$ & \\
\hline \multicolumn{4}{|l|}{ Educational level } \\
\hline $\begin{array}{l}\text { No formal Educa- } \\
\text { tion }\end{array}$ & $1(0.3)$ & $1(0.3)$ & \\
\hline Primary education & $9(2.9)$ & $3(1.0)$ & $<0.001^{*}$ \\
\hline $\begin{array}{l}\text { Secondary educa- } \\
\text { tion }\end{array}$ & $114(36.8)$ & $52(16.8)$ & \\
\hline $\begin{array}{l}\text { Post-secondary } \\
\text { education }\end{array}$ & $186(60.0)$ & $254(81.9)$ & \\
\hline \multicolumn{4}{|l|}{ Religious Denomination } \\
\hline Catholic & $153(49.4)$ & $145(46.8)$ & 0.819 \\
\hline Anglican/Protestant & $53(17.1)$ & $51(16.4)$ & \\
\hline Others & $6(1.9)$ & $5(1.6)$ & \\
\hline Pentecostal & $98(31.6)$ & $109(35.2)$ & \\
\hline \multicolumn{4}{|l|}{ Employment status } \\
\hline Unemployed & $47(15.2)$ & $51(16.5)$ & $0.005^{*}$ \\
\hline Self-employment & $124(40.0)$ & $86(27.7)$ & \\
\hline Paid employment & $139(44.8)$ & $173(55.8)$ & \\
\hline \multicolumn{4}{|l|}{ Place of Residence } \\
\hline Rural & $123(39.7)$ & $31(10.0)$ & $<0.001^{*}$ \\
\hline Urban & $187(60.3)$ & $279(90.0)$ & \\
\hline \multicolumn{4}{|c|}{ Duration post-childbirth } \\
\hline 0-6 weeks & $168(54.2)$ & $131(42.3)$ & $0.003^{*}$ \\
\hline 7-14 weeks & 142(45.8) & 179(57.7) & \\
\hline \multicolumn{4}{|l|}{ Socioeconomic quartiles } \\
\hline $\begin{array}{l}1^{\text {st }} \text { Quartile (Poor- } \\
\text { est) }\end{array}$ & $126(40.6)$ & $29(9.4)$ & $<0.001 *$ \\
\hline $\begin{array}{l}2^{\text {nd }} \text { Quartile (Very } \\
\text { poor) }\end{array}$ & $87(28.1)$ & $69(22.3)$ & \\
\hline $3^{\text {rd }}$ Quartile (Poor) & $59(19.0)$ & $95(30.6)$ & \\
\hline $\begin{array}{l}4^{\text {th }} \text { Quartile (Least } \\
\text { poor) }\end{array}$ & $38(12.3)$ & $117(37.7)$ & \\
\hline
\end{tabular}

*statistical significance $+\mathrm{t}$-test

proportion of participants in the public hospital were paid employees compared to their private hospital counterparts $(55.8 \%$ vs. $44.8 \% ; p=0.005)$. A higher proportion of participants in the public hospital belonged to the upper socioeconomic quartile (37.7\% vs. $12.3 \%$; $p<0.001)$ (Table 1).
Overall, most different forms and types of D\&A during childbirth were very frequent in both hospitals. The highest prevalence of D\&A forms in both facilities were being beaten, slapped or pinched [public23 (7.4\%) vs. private19 (6.1\%)], episiotomy without consent [public 12 (5.5\%) vs. private $23(7.4 \%)$ ], and augmentation of labour without consent [public $24(7.7 \%)$ vs. private $16(5.2 \%)]$. In the public hospital, less women 4 (1.3\%) had their pubic hair shaved without consent than in the private hospital 18 (5.8\%) [cOR 0.21; 95\% CI. 0.07, 0.63] (Table 2).

A lower proportion of women experienced nonconsented care in the public hospital $45(14.5 \%)$ compared to their private hospital counterparts 67 (21.6) [cOR 0.62; 95\% CI. 0.41, 0.93] (Table 3). The proportion of women who reported at least one form of D\&A in the public hospital was significantly higher [Public 191 (61.6\%) vs. Private 156 (50.3\%): cOR 1.58; 95\% CI. 1.15, 2.18] Abandonment and neglect was reported by 153 (49.4\%) of women in the public hospital compared to 91 (29.4\%) in the private hospital [COR 2.35; 95\% CI. 1.69, 3.26] (Table 3). Denial of companionship by the hospitals was the most reported subtype of D\&A during childbirth in both facilities and this was higher in the public health facility [Public 135 (43.5\%) vs. Private 66 (21.3\%): cOR 2.85; 95\% CI. 2.00, 4.06]. In the public hospital, fewer women were detained after childbirth because of inability to pay up bills for themselves [Public 8 (2.6\%) vs. Private 21 (6.8\%): cOR $0.37 ; 95 \%$ CI. $0.16,0.84]$ as well as for the baby [Public 4 (1.3\%) vs. Private 14 (4.5\%): cOR 0.28; $95 \%$ CI. $0.09,0.85]$. There were no differences in the mean number of D\&A during childbirth between the two facilities (Public1.04 $\pm 1.12 v s$. Private1.00 $\pm 1.33 ; P=0.613$ ) (Table 3).

In the multivariable logistic regression model, women who resided in the rural areas had $47 \%$ lower odds of reporting at least one form of D\&A during childbirth (aOR 0.53; CI 0.35-0.79) (Table 4).

\section{Discussion \\ Principal findings}

More women had post-secondary education and belonged to the uppermost wealth quartile in the public hospital rather than those in the private one. This finding could be because in the context of the study area, teaching hospitals (the public hospital in this study) are well known to offer a wider range of specialist care in addition to employing higher numbers of skilled health workers and these may be better appreciated and sought after by those who are more educated and can better afford this care because they are in the upper wealth quartiles. However, the population in these two hospitals may be different from the distribution of education and wealth quartiles in the general population in Nigeria $[9,33]$. 
Table 2 Prevalence of physical abuse, non-consented, non-confidential and discriminatory care during childbirth

\begin{tabular}{|c|c|c|c|c|}
\hline \multirow[t]{2}{*}{ Variable } & \multirow{2}{*}{$\begin{array}{l}\text { Public hospital } \\
(n=310) \\
\text { Yes }(\%)\end{array}$} & \multirow{2}{*}{$\begin{array}{l}\text { Private hospital } \\
(n=310) \\
\text { Yes }(\%)\end{array}$} & \multirow[t]{2}{*}{$\begin{array}{l}\text { Crude Odds } \\
\text { ratio }\end{array}$} & \multirow[t]{2}{*}{$95 \% \mathrm{Cl}$} \\
\hline & & & & \\
\hline \multicolumn{5}{|l|}{ Physical Abuse } \\
\hline Episiotomy given or sutured without anaesthesia & $12(3.9)$ & $22(7.1)$ & 0.53 & $0.26-1.09$ \\
\hline Beaten, slapped or pinched & $23(7.4)$ & $19(6.1)$ & 1.16 & $0.62-2.16$ \\
\hline Tied down or restrained during labour & $6(1.9)$ & $10(3.2)$ & 0.59 & $0.21-1.65$ \\
\hline Other ways of physical abuse $\mathrm{e}^{\mathrm{b}}$ & $2(0.6)$ & $6(1.9)$ & 0.33 & $0.07-1.64$ \\
\hline Sexually abused by health worker during labour & $0(0.0)$ & $3(1.0)$ & e & e \\
\hline \multicolumn{5}{|l|}{ Non-consented care } \\
\hline Episiotomy without consent & $12(5.5)$ & 23(7.4) & 0.72 & $0.38-1.38$ \\
\hline Shaving of pubic hair without consent & $4(1.3)$ & 18(5.8) & 0.21 & $0.07-0.63^{a}$ \\
\hline Augmentation of labour without consent & $24(7.7)$ & $16(5.2)$ & 1.54 & $0.80-2.96$ \\
\hline Caesarean birth without consent & $7(2.3)$ & $16(5.2)$ & 0.43 & $0.17-1.05$ \\
\hline Blood transfusion without consent & $3(1.0)$ & 10(3.2) & 0.29 & $0.08-1.08$ \\
\hline Sterilization without consent & $3(1.0)$ & $7(2.3)$ & 0.42 & $0.11-1.65$ \\
\hline Other services without consent ${ }^{c}$ & $3(1.0)$ & $8(2.6)$ & 0.37 & $0.09-1.40$ \\
\hline \multicolumn{5}{|l|}{ Non-confidential care } \\
\hline Provision of care without privacy & $4(1.3)$ & $8(2.6)$ & 0.49 & $0.15-1.66$ \\
\hline Medical history disclosure without consent & $1(0.3)$ & $7(2.3)$ & 0.14 & $0.02-1.15$ \\
\hline Age disclosure without consent & $2(0.6)$ & $6(1.9)$ & 0.34 & $0.07-1.64$ \\
\hline Disclosure of child's paternity without consent & $2(0.6)$ & $5(1.6)$ & 0.40 & $0.08-2.06$ \\
\hline Disclosure of HIV status without consent & $0(0.0)$ & $4(1.3)$ & e & e \\
\hline Other forms of non-confidential care ${ }^{d}$ & $1(0.3)$ & $4(1.3)$ & 0.25 & $0.03-2.23$ \\
\hline \multicolumn{5}{|l|}{ Discriminatory care } \\
\hline $\begin{array}{l}\text { Denial of needed attention because of low social class or socio-eco- } \\
\text { nomic status }\end{array}$ & $1(0.3)$ & $4(1.3)$ & 0.25 & $0.03-2.23$ \\
\hline Denial of needed attention because of teen age ( $\leq 19$ years) & $0(0)$ & $2(0.6)$ & e & e \\
\hline Denial of needed attention because of single motherhood status & $1(0.3)$ & $2(0.6)$ & 0.49 & $0.05-5.53$ \\
\hline Denial of needed attention because of HIV-seropositive status & $0(0)$ & $2(0.6)$ & e & e \\
\hline Denial of needed attention because of low educational status & $3(1.0)$ & $1(0.3)$ & 3.02 & $0.31-29.19$ \\
\hline Denial of needed attention on the basis of ethnicity & $1(0.3)$ & $0(0.0)$ & e & e \\
\hline Other reasons for discriminatory care & $1(0.3)$ & $0(0.0)$ & e & e \\
\hline
\end{tabular}

${ }^{a}$ Statistical significance ${ }^{\mathrm{b}}$ shoving and handling roughly $\mathrm{C}$ Intravenous access and vaginal examination without consent ${ }^{\mathrm{d}}$ Discussion of medical history and clinical examination with/in the presence of medical students ${ }^{\text {e }}$ Odds ratio was not calculable for variables with empty cells.

The prevalence of abandonment and neglect during childbirth was the major category of D\&A experienced in both hospitals. These were all statistically significantly higher in the public hospital as compared to the private hospital. The difference in prevalence of abandonment/ neglect during childbirth between the public and private hospital could be because the public hospital is a bigger referral hospital (the only teaching hospital in the State) and may also have more women referred for complications than the private hospital. This could overwhelm the ability of the staff leading to perceived feelings of being abandoned. On the other hand, staff may become more friendly with women who have complications than with those who have no complications. Consistent with our findings, abandonment was among the most reported forms of D\&A during childbirth in other studies [19, $23,34-36]$. This high prevalence of abandonment is particularly worrisome because the assured availability of a health provider during childbirth is an aspect of care considered important by women who have passed through the childbirth process [37]. Under this abandonment category, being denied companionship in labour by the husband or close relatives was most often reported. Companionship during labour and childbirth have been found to improve maternal mental wellbeing and obstetric outcomes [38]. Nonetheless, implementation of this effective and affordable intervention has remained suboptimal in many settings such as ours $[38,39]$. On the 
Table 3 Prevalence of abandonment/neglect, non-dignified care and detention following childbirth and at least one form of D\&A during childbirth

\begin{tabular}{|c|c|c|c|c|}
\hline \multirow[t]{2}{*}{ Variable } & $\begin{array}{l}\text { Public } \\
\text { hospital } \\
(n=310)\end{array}$ & $\begin{array}{l}\text { Private } \\
\text { hospital } \\
(n=310)\end{array}$ & Odds ratio & $95 \% \mathrm{Cl}$ \\
\hline & Yes (\%) & Yes (\%) & & \\
\hline \multicolumn{5}{|l|}{ Abandonment/Neglect } \\
\hline Denied companionship in labour & $135(43.5)$ & $66(21.3)$ & 2.85 & $2.00-4.06^{\circ}$ \\
\hline Left alone unattended in second stage of labour & $23(7.4)$ & $17(5.5)$ & 1.38 & $0.72-2.64$ \\
\hline $\begin{array}{l}\text { Birth attendant failed to intervene or call for help from experienced staff in life threatening } \\
\text { conditions }\end{array}$ & $12(3.9)$ & $13(4.2)$ & 0.92 & $0.41-2.05$ \\
\hline Not granted requested attention because staff was exhausted & $12(3.9)$ & $11(3.5)$ & 1.10 & $0.48-2.52$ \\
\hline Abandoned/neglected for other reasons & $15(4.8)$ & $7(2.3)$ & 2.20 & $0.89-5.48$ \\
\hline \multicolumn{5}{|l|}{ Non-dignified care } \\
\hline $\begin{array}{l}\text { Threatened with Caesarean section or poor pregnancy outcome in order to discourage } \\
\text { women from shouting in labour }\end{array}$ & $30(9.7)$ & $31(10.0)$ & 0.96 & $0.57-1.64$ \\
\hline Scolded, shouted at or called stupid while in labour & $36(11.6)$ & $27(8.7)$ & 1.38 & $0.81-2.33$ \\
\hline Received slanderous remarks (aspersions) from birth attendants during labour & $21(6.8)$ & $20(6.5)$ & 1.05 & 0.56-1.99 \\
\hline Blamed or intimidated during childbirth & $13(4.2)$ & $16(5.2)$ & 0.80 & $0.38-1.70$ \\
\hline Other forms of non-dignified care" & $4(1.3)$ & $4(1.3)$ & 1.00 & $0.25-4.04$ \\
\hline \multicolumn{5}{|l|}{ Detention in the health facility following childbirth } \\
\hline You could not pay up your hospital bills at discharge & $8(2.6)$ & $21(6.8)$ & 0.37 & $0.16-0.84^{a}$ \\
\hline You could not pay up baby's hospital bills at discharge & $4(1.3)$ & $14(4.5)$ & 0.28 & $0.09-0.85^{\mathrm{a}}$ \\
\hline Other reasons ${ }^{c}$ & $4(1.3)$ & $3(1.0)$ & 1.34 & $0.30-6.03$ \\
\hline At least one form of $D \& A$ during childbirth & 191(61.6) & 156(50.3) & 1.58 & $1.15-2.18^{\mathrm{a}}$ \\
\hline \multicolumn{5}{|l|}{ Categories of D\&A during childbirth } \\
\hline Abandonment and neglect & 153(49.4) & $91(29.4)$ & 2.35 & $1.69-3.26$ \\
\hline Non-consented care & $45(14.5)$ & $67(21.6)$ & 0.62 & $0.41-0.93^{a}$ \\
\hline Non-dignified care & $61(19.7)$ & $57(18.4)$ & 0.62 & $0.41-0.93^{a}$ \\
\hline Physical abuse & $39(12.6)$ & $45(14.5)$ & 0.85 & $0.53-1.34$ \\
\hline Detention & $12(3.9)$ & $25(8.1)$ & 0.46 & $0.23-0.93^{a}$ \\
\hline Non-confidential care & $9(2.9)$ & $16(5.2)$ & 0.55 & $0.24-1.26$ \\
\hline Discriminatory care & $6(1.9)$ & $7(2.3)$ & 0.85 & $0.28-2.57$ \\
\hline Mean number of D\&A & $1.04 \pm 1.12$ & $1.00 \pm 1.33$ & & \\
\hline Maximum number of D\&A & 6 & 5 & & \\
\hline Minimum number of D\&A & 0 & 0 & - & \\
\hline
\end{tabular}

a Statistical significance D\&A: Disrespect and Abuse"Threatened with abandonment to discourage uncooperativeness and rudeness to birth companions/relatives 'Detained on account of unsatisfactory health status of mother and/or child which mother perceived as satisfactory and/or a guise for increased hospital bills

other hand, non-consented and non-dignified care were most commonly reported in other studies [18, 40].

In contrast to our findings, other studies (also in teaching hospitals) found higher proportions of nonconsented care during childbirth (54\%-100\%) . An explanation could be that women in those studies were interviewed earlier after birth than in ours. Findings from other studies are consistent with the different forms of non-consented care in our study [18, 23, 34, 41]. In line with ethical best practices, informed consent is supposed to be obtained from women before any procedure is carried out. These reports of non-consented care are a breach of ethical principles and highlight the need to improve ethics-based obstetric practices. One reason for this could be that in resource-limited environments, litigations related to such matters are relatively uncommon and the implicit assumption that health providers are to make decisions regarding maternity care for women with or without their informed consent $[18,42]$.

Non-dignified care was also commonly reported in this study however more respondents (29.6\%) experienced non-dignified care in another Nigerian study [18], while it was the commonest type of D\&A meted out to women during childbirth in Mali [43]. 
Table 4 Predictors of at least one form of D\&A during childbirth $(n=620)$

\begin{tabular}{|c|c|c|c|}
\hline \multirow[t]{2}{*}{ Variable } & \multirow{2}{*}{$\begin{array}{l}\text { adjusted } \\
\text { Odds Ratio }\end{array}$} & \multicolumn{2}{|l|}{$95 \% \mathrm{Cl}$} \\
\hline & & Lower & Upper \\
\hline \multicolumn{4}{|l|}{ Employment status } \\
\hline Unemployed & 1.46 & 0.93 & 2.30 \\
\hline Employed & 1 & & \\
\hline \multicolumn{4}{|l|}{ Place of Residence } \\
\hline Rural & 0.53 & 0.35 & 0.79 \\
\hline Urban & 1 & & \\
\hline \multicolumn{4}{|l|}{ Socioeconomic status } \\
\hline Low socioeconomic status & 1.09 & 0.76 & 1.56 \\
\hline High socioeconomic status & 1 & & \\
\hline \multicolumn{4}{|l|}{ Duration after birth } \\
\hline 0-6weeks & 0.87 & 0.63 & 1.21 \\
\hline 7-14 weeks & 1 & & \\
\hline \multicolumn{4}{|l|}{ Birthing facility type } \\
\hline Private & 0.74 & 0.52 & 1.06 \\
\hline Public & 1 & & \\
\hline
\end{tabular}

Discriminatory care during childbirth has been documented in our and other studies [18, 44]. Discriminating against a parturient for any reason breaches the fundamental health rights of women. Thus there is need for continuous training and supervision of obstetric healthcare providers in order to ensure non-discrimination in patient care.

The prevalence of at least one form of D\&A during childbirth was high in both hospitals, but significantly higher in the public hospital.

Women were interviewed in the health facility where their childbirth had occurred and this could have introduced courtesy bias. It has been suggested, however, that a longer period after birth may allow time for mental processing the birth experience and thus improve recall. Alternatively, a different school of thought opines that women may tend to forget the nasty birth experiences the longer the time passed between the experience and the survey [45]. A study among women in Ethiopia, Kenya, Madagascar, Rwanda and Tanzania reported a prevalence of $60 \%$ of overall violations of respectful maternity care rights following objective assessment using a structured checklist [19]. Observation of women-provider interactions by trained observers in an Ethiopian study found a prevalence of $74.8 \%$, nonetheless, only $22 \%$ of the women reported D\&A during childbirth [23]. Normalization of D\&A during childbirth by mothers in the study may have made them fail to consider and/or report certain disrespectful practices leading to the incongruence between observed and self-reported events. Objective assessment of D\&A by trained observers using structured checklists have shown to provide higher prevalence estimates of $\mathrm{D} \& \mathrm{~A}$ during childbirth than subjective reporting [46]. Self-reported prevalence of D\&A during childbirth in our study may thus have been underestimated. A review of D\&A during childbirth in Ethiopia and sub-Saharan Africa found a pooled prevalence of $44 \%-49.4 \%[35,36]$. Beyond being pooled estimates, the lower prevalence in these reviews may be because some of those studies were community-based and involved women at different points in time after birth.

Disparities that could account for the prevalence of at least one form of D\&A in both hospitals include the fact that private hospitals, especially mission hospitals, tend to have more stringent measures in place to ensure respect for women. This includes close supervision of staff and oversight of the facility by the church, ready patient's access to hospital or church management for complaints of disrespectful care and follow-up of such complaints in addition to the moralistic undertone with which care is rendered in private hospitals. Also, such hospitals may attract patronage from faithful people who may have more religion-related acceptance for provided health care. In contrast, bureaucratic processes, poor ownership attitudes by workers and loose redressing mechanisms have been associated with public hospitals $[47,48]$.

Our findings portray the need to improve maternity experiences of parturient and build an institutional culture of respectful care. This will include systematic identification of underlying contributors to D\&A during childbirth as well as designing and implementing context-specific interventions to address these in the two facilities. Such interventions may involve development of institutional indicators of D\&A during childbirth, their routine evaluation and using lessons learned to improve maternity experiences of women during childbirth. It is equally important to institutionalize continuous provider training, mentorship, monitoring and supportive supervision that build interpersonal communication skills aimed at promoting woman-centred care in both public and private health care settings. Such training can be integrated into existing facility-based continuous educational platforms such as grand rounds, professional group seminars and morning reviews. This is in addition to the use of provider-independent mechanisms and checks such as automated and administrative processes that routinize procedures such as informed consent before 
clinical care is provided. An emerging nascent area of focus from our study is the need for cross-learning and collaboration between the public and private health sectors, all geared towards improving maternal experiences of maternity care.

Previous studies have shown that women who resided in rural areas reported less D\&A during childbirth than those residing in urban areas, in line with our findings $[49,50]$. In other studies, being older than 19 years, having no formal education, at least ninth grade and secondary education, self-reported depression, absence of support persons during childbirth, longer labour duration, and birth via Caesarean section were more likely to experience D\&A during childbirth while parity (more than four births) reduced the likelihood [49-51].

Women who reside in rural areas tend to be poorer, less educated, less equipped with materials for childbirth, less aware of their rights and thus more prone to experience D\&A during labour and childbirth without recognizing it. Structural gender inequities evidenced by paucity of information, lack of financial stability and autonomy to exercise rights contribute to perpetuating D\&A during childbirth [52]. Additionally, rural women may be more inclined to consider such 'mistreatments' as normal given culture-related patriarchal settings of rural African communities and expected subservience of women [53]. Their urban counterparts may be more knowledgeable about their rights and have higher expectations regarding their healthcare experiences with more openness in sharing D\&A during childbirth. These findings highlight the need for intersectoral collaboration targeted at improving the status of women through female education, financial empowerment, awareness of rights and support for justice.

Some areas for future research would include the use of observations in estimating the prevalence and isolating enablers of D\&A during childbirth from the perspectives of women and health providers in a larger number of public and private hospitals. Future research is also needed to develop and assess the effectiveness of contextually relevant interventions to reduce D\&A during childbirth in both public and private health care settings.

\section{Strengths and limitations}

This is one of the few studies in Nigeria that have estimated prevalence of D\&A during childbirth with quantitative methods. More so, to the best of our search, this is one of the first studies to compare experiences of D\&A in public and private health care settings. Lastly, this study utilized a fairly large sample. Some limitations include the fact that it was conducted in only two facilities which were non-randomly selected. Additionally, the fact that women who did not return to immunization clinics could not be interviewed, was a possible source of selection bias. This study was not based on observational data, but on self-reports which is prone to courtesy bias. Use of the Bowser and Hill's framework for D\&A during childbirth did not permit exploitation of professional and structural/systemic definitions of mistreatment during childbirth as defined by Bohren et al. [7]

The survey was conducted in a hospital setting and by health workers, thus introducing courtesy bias due to women's fear of aftermaths and non-confidentiality of their responses. Normalization of D\&A during childbirth and fear of indicting health workers may have led to socially desirable responses. These could have resulted in underestimation of D\&A during childbirth in both facilities. To mitigate this, different domains of D\&A during childbirth were thoroughly explained and women were encouraged to give sincere responses. They were also assured of confidentiality and non-penalization for their responses.

Recall bias could have affected responses, given that the study was conducted from childbirth to 14 weeks thereafter. Conversely, a short recall period may lead to underreporting as women may be too fatigued to accurately relate their birth experiences. A longer recall period affords more time for women to recollect and correctly report their experiences. On the other hand, women may tend to forget these experiences as the newborn develops well [45]. Involvement of the researcher and other health providers in data collection may have introduced observer bias possibly underestimating the burden of D\&A during childbirth. The researchers, however, were not directly involved in maternity care and were trained on data collection techniques. Finally, this study was conducted in only two facilities offering specialist care and given the age and educational profiles of the participants, it may not be generalizable to lower levels of care and the general population.

\section{Conclusion}

A greater proportion of women who gave birth in the public hospital experienced at least one form of D\&A during childbirth compared to those in the private one. Prevalence, however, was very high in both facilities. Abandonment/neglect and non-consented care were the two commonest forms of D\&A in the private hospital, while in the public hospital abandonment and non-dignified care were the most frequent forms. Contextual barriers to respectful and non-abusive care of women during 
childbirth in both public and private health care settings need much more focus to be identified and addressed. We recommend adoption of a systems thinking approach in curbing various forms of D\&A during childbirth highlighted in this study.

\section{Abbreviations}

AOR: Adjusted Odds ratio; Cl: Confidence Interval; COR: Crude Odds ratio; D\&A: Disrespect and Abuse; MNH: Maternal and New born Health; PCA: Principal Component Analysis; RMC: Respectful Maternity Care; SD: Standard Deviation; SBA: Skilled Birth Attendants; SPSS: Statistical Package for Social Sciences; WHO: World Health Organization.

\section{Supplementary Information}

The online version contains supplementary material available at https://doi. org/10.1186/s12884-021-04298-z.

\section{Additional file 1.}

Additional file 2 .

Additional file 3.

\section{Acknowledgements}

We appreciate all the women who participated in this study

\section{Authors' contributions}

INO: Study conceptualization and design, data collection, analysis and interpretation of results, manuscript drafting and approval of the final manuscript for publication. ICA: Study design, data collection, analysis and interpretation of results, manuscript drafting and approval of the final manuscript for publication. IIE: Study design, data collection, manuscript drafting and approval of the final manuscript for publication. CNO: Study design, data collection, manuscript drafting and approval of the final manuscript for publication.

\section{Funding}

This research was funded by the authors.

\section{Availability of data and materials}

The datasets used and/or analyzed during the current study are available from the corresponding author on reasonable request.

\section{Declarations}

\section{Ethics approval and consent to participate}

Ethical approval for this study was obtained from the Research and Ethics Committee of Alex-Ekwueme Federal University Teaching Hospital Abakaliki, Ebonyi State of Nigeria with approval number 06/10/2017-23/20/2017.Written informed consent for participation in the study was obtained from all women and not from a parent or guardian as there was no participant under $16 y e a r s$ of age.

\section{Consent for publication}

Not required.

\section{Competing interests}

We declare that there are no competing interests.

\section{Author details}

'Department of Community Medicine, Alex Ekwueme Federal University Teaching Hospital Abakaliki, Abakaliki, Ebonyi State, Nigeria. ${ }^{2}$ African Institute for Health Policy and Health Systems, Ebonyi State University, Abakaliki, Nigeria.
Received: 1 May 2020 Accepted: 29 November 2021

Published online: 31 December 2021

\section{References}

1. White Ribbon Alliance. Respectful maternity care: The universal rights of childbearing women, www.whiteribbonalliance.org/respectfulcare (2010, accessed 12 August 2017).

2. World Health Organization. The prevention and elimination of disrespect and abuse during facility-based childbirth:WHO statement. Geneva, Switzerland, http://apps.who.int/iris/bitstream/10665/134588/1/WHO_ RHR_14.23 eng.pdf?ua $=1 \&$ ua $=1$ (2014, accessed 9 February 2017).

3. Tunçalp Ö, Were W, MacLennan C, et al. Quality of care for pregnant women and newborns-the WHO vision.BJOG. 2015;122:1045-9.

4. World Health Organization. Standards for improving quality of maternal and newborn care in health facilities. Geneva, http://www.who.int/mater nal_child_adolescent/documents/improving-maternal-newborn-carequality/en/ (2017, accessed 13 September 2017).

5. Miller S, Lalonde A. The global epidemic of abuse and disrespect during childbirth : History, evidence, interventions, and FIGO 's mother - baby friendly birthing facilities initiative. Int J Gynecol Obstet. 2015:131:S49-52.

6. Hameed W, Avan BI. Women's experiences of mistreatment during childbirth: A comparative view of home- and facility-based births in Pakistan. PLoS One. 2018;13:e0194601.

7. Bohren MA, Vogel JP, Hunter EC, et al. The Mistreatment of Women during Childbirth in Health Facilities Globally: A Mixed-Methods Systematic Review. PLos Med. 2015;12:1-32.

8. Bowser D, Hill K. Exploring Evidence for Disrespect and Abuse in FacilityBased Childbirth: Report of a Landscape Analysis. New York, https://www. ghdonline.org/uploads/Respectful_Care_at_Birth_9-20-101_Final1.pdf (2010, accessed 5 March 2018).

9. National Population Commission (NPC) [Nigeria] and The DHS Program ICF Rockville, Maryland U. Nigeria Demographic and Health Survey 2018. Abuja, Nigeria and Rockville, Maryland, USA, 2019.

10. Ishola F, Owolabi O, Filippi V. Disrespect and abuse of women during childbirth in Nigeria : A systematic review. PLoS One. 2017;12:e0174084.

11. Uwakwe KA, Merenu IA, Duru CB, et al. Patterns of utilization of orthodox and / or traditional healthcare services among pregnant women and mothers of under - five children in a rural community: Case study of Njaba, Imo State, Nigeria. Sahel Med J. 2015;18:103-8.

12. Freedman L, Kruk M. Disrespect and abuse of women in childbirth : challenging the global quality and accountability agendas. Lancet. 2014:384:e42-4.

13. Mselle LT, Moland KM, Mvungi A, et al. Why give birth in health facility? users' and providers' accounts of poor quality of birth care in Tanzania. BMC Health Serv Res. 2013;13:174.

14. Roro MA, Hassen EM, Lemma AM, et al. Why do women not deliver in health facilities : a qualitative study of the community perspectives in south central Ethiopia? BMC Res Notes. 2014;7:1-7.

15. Bohren MA, Hunter EC, Munthe-kaas HM, et al. Facilitators and barriers to facility-based delivery in low- and middle-income countries: a qualitative evidence synthesis. Reprod Health. 2014;11:71.

16. Sychareun V, Hansana V, Somphet V, et al. Reasons rural Laotians choose home deliveries over delivery at health facilities : a qualitative study. BMC Pregnancy Childbirth. 2012;12:86.

17. Wilunda C, Scanagatta C, Putoto G, et al. Barriers to Institutional Childbirth in Rumbek North County, South Sudan: A Qualitative Study. PLoS One. 2016;11:e0168083.

18. Okafor II, Ugwu EO, Obi SN. Disrespect and abuse during facility-based childbirth in a low-income country. Int J Gynecol Obstet. 2015;128:110-3.

19. Rosen HE, Lynam PF, Carr C, et al. Direct observation of respectful maternity care in five countries: a cross-sectional study of health facilities in East and Southern Africa. BMC Pregnancy Childbirth. 2015;15:1-11.

20. Bohren MA, Vogel JP, Tunçalp Ö, et al. "By slapping their laps, the patient will know that you truly care for her": A qualitative study on social norms and acceptability of the mistreatment of women during childbirth in Abuja, Nigeria. SSM - Popul Heal. 2016;2:640-55. 
21. Bohren MA, Vogel JP, Tunçalp Ö, et al. Mistreatment of women during childbirth in Abuja, Nigeria : a qualitative study on perceptions and experiences of women and healthcare providers. Reprod Health. 2017;14:9.

22. Balde MD, Diallo BA, Bangoura A, et al. Perceptions and experiences of the mistreatment of women during childbirth in health facilities in Guinea : a qualitative study with women and service providers. Reprod Health. 2017;14:3.

23. Asefa A, Bekele D. Status of respectful and non-abusive care during facility-based childbirth in a hospital and health centers in Addis Ababa Ethiopia. Reprod Health. 2015;12:33.

24. Orpin J, Puthussery S, Davidson R, et al. Women's experiences of disrespect and abuse in maternity care facilities in Benue State, Nigeria. BMC Pregnancy Childbirth. 2018;18:213.

25. Moyer CA, Rominski S, Nakua EK, et al. Exposure to disrespectful patient care during training: Data from midwifery students at 15 midwifery schools in Ghana. Midwifery. 2016;41:39-44.

26. Moyer CA, Adongo PB, Aborigo RA, et al. 'They treat you like you are not a human being ': Maltreatment during labour and delivery in rural northern Ghana. Midwifery. 2014;30:262-8.

27. Rominski SD, Lori J, Nakua E, et al. When the baby remains there for a long time, it is going to die so you have to hit her small for the baby to come out: Justification of disrespectful and abusive care during childbirth among midwifery students in Ghana. Health Policy Plan. 2017;32:215-24.

28. Denscombe $M$. The good research guide for small scale social research projects. 4th ed. London: Open University Press; 2010.

29. Nwaze I. A practical guide to research in the field of health and biostatistics. Abakaliki: Guzan publishers; 2002.

30. StataCorp. Stata statistical software: Release 12.

31. Uzochukwu BSC, Onwujekwe OE. Socio-economic differences and health seeking behaviour for the diagnosis and treatment of malaria: A case study of four local government areas operating the Bamako initiative programme in south-east Nigeria. Int J Equity Health. 2004;3:1-10.

32. IBM Corp. Released 2011. IBM SPSS Statistics for Windows, Version 20.0. Armonk, NY: IBM Corp.

33. National Bureau of statistics. Nigeria Poverty Profile 2010. Abuja, http:// www.nigerianstat.gov.ng/pdfuploads/NigeriaPovertyProfile2010.pdf (2010, accessed 8 September 2017).

34. Sheferaw ED, Bazant E, Gibson H, et al. Respectful maternity care in Ethiopian public health facilities. Reprod Health. 2017;14:1-12.

35. Kassa $Z Y$, Tsegaye $B$, Abeje A. Disrespect and abuse of women during the process of childbirth at health facilities in sub-Saharan Africa : a systematic review and. BMC Int Health Hum Rights. 2020;20:23.

36. Kassa ZY, Husen S. Disrespectful and abusive behavior during childbirth and maternity care in Ethiopia : a systematic review and meta - analysis. BMC Res Notes. 2019;12:83.

37. Bhattacharyya S, Srivastava A, Avan BI. Delivery should happen soon and my pain will be reduced: understanding women's perception of good delivery care in India. Glob Health Action. 2013;6:e22635.

38. Bohren M, Berger B, Munthe-Kaas H, et al. Perceptions and experiences of labour companionship: a qualitative evidence synthesis. Cochrane Database Syst Rev. 2019;3:CD012449.

39. Vogel JP, Bohren MA, Tunçalp O, et al. Promoting respect and preventing mistreatment during childbirth. BJOG. 2016;123:671-4.

40. Jungari S, Sharma B, Wagh D. Beyond Maternal Mortality : A Systematic Review of Evidences on Mistreatment and Disrespect During Childbirth in Health Facilities in India. Trauma Violence Abuse. 2019;XX:1-13.

41. Amroussia N, Hernandez A, Vives-cases C, et al. "Is the doctor God to punish me ?! "An intersectional examination of disrespectful and abusive care during childbirth against single mothers in Tunisia. Reprod Health. 2017; 14:32

42. Sadler M, Santos MJ, Ruiz-Berdún D, et al. Moving beyond disrespect and abuse: addressing the structural dimensions of obstetric violence. Reprod Health Matters. 2016;24:47-55.

43. Warren $\mathrm{N}$, Beebe $\mathrm{M}$, Chase RP, et al. $\mathrm{N}$ è g è $\mathrm{n}$ è $\mathrm{g}$ è $\mathrm{n}:$ Sweet talk, disrespect, and abuse among rural auxiliary midwives in Mali. Midwifery. 2015:31:1073-80.

44. Sudhinaraset M, Treleaven E, Melo J, et al. Women 's status and experiences of mistreatment during childbirth in Uttar Pradesh : a mixed methods study using cultural health capital theory. BMC Pregnancy Childbirth; 26. Epub ahead of print 2016. https://doi.org/10.1186/ s12884-016-1124-4.
45. Sando D, Abuya T, Asefa A, et al. Methods used in prevalence studies of disrespect and abuse during facility based childbirth: Lessons learned. Reprod Health. 2017;14:127.

46. Azhar Z, Oyebode O, Masud H. Disrespect and abuse during childbirth in district Gujrat, Pakistan: A quest for respectful maternity care. Ann Glob Heal. 2017:83:108

47. Iloh G, Ofoedu J, Njoku P, et al. Satisfaction with Quality of Care Received by Patients without National Health Insurance Attending a Primary Care Clinic in a Resource-Poor Environment of a Tertiary Hospital in. Ann Med Heal Sci Res. 2013;3:31-7.

48. Okonofua F, Ogu R, Agholor K, et al. Qualitative assessment of women 's satisfaction with maternal health care in referral hospitals in Nigeria. Reprod Health. 2017;14:44.

49. Ukke GG, Gurara MK, Boynito WG. Disrespect and abuse of women during childbirth in public health facilities in Arba Minch town, South Ethiopia - a cross-sectional study. PLoS One. 2019;14:e0205545.

50. Gebremichael MW, Worku A, Medhanyie AA, et al. Mothers 'experience of disrespect and abuse during maternity care in northern Ethiopia. Glob Health Action; 11. Epub ahead of print 2018. https://doi.org/10.1080/ 16549716.2018 .1465215$.

51. Kruk ME, Kujawski S, Mbaruku G, et al. Disrespectful and abusive treatment during facility delivery in Tanzania : a facility and community survey. Health Policy Plan. 2014;33:1-8.

52. Betron ML, Mcclair TL, Currie S, et al. Expanding the agenda for addressing mistreatment in maternity care : a mapping review and gender analysis. Reprod Health. 2018;15:143.

53. Abuya T, Warren C, Bellows B, et al. Exploring the Prevalence of Disrespect and Abuse during Childbirth in Kenya. PLoS One. 2015;10:e0123606.

\section{Publisher's Note}

Springer Nature remains neutral with regard to jurisdictional claims in published maps and institutional affiliations.

Ready to submit your research? Choose BMC and benefit from:

- fast, convenient online submission

- thorough peer review by experienced researchers in your field

- rapid publication on acceptance

- support for research data, including large and complex data types

- gold Open Access which fosters wider collaboration and increased citations

- maximum visibility for your research: over $100 \mathrm{M}$ website views per year

At BMC, research is always in progress.

Learn more biomedcentral.com/submissions 